\title{
TRANS-STRIATAL DIALYSIS COUPLED TO REVERSE PHASE HIGH PERFORMANCE LIQUID CHROMATOGRAPHY WITH ELECTROCHEMICAL DETECTION: A NEW METHOD FOR THE STUDY OF THE IN VIVO RELEASE OF ENDOGENOUS DOPAMINE AND METABOLITES ${ }^{1}$
}

\author{
ASSUNTA IMPERATO AND GAETANO DI CHIARA ${ }^{2}$ \\ Institute of Experimental Pharmacology and Toxicology, University of Cagliari, 09100 Cagliari, Italy
}

Received July 6, 1983; Revised October 3, 1983; Accepted October 14, 1983

\begin{abstract}
A method for the estimation in rats of the in vivo release and metabolism of dopamine (DA) is described. The method is based on the dialysis principle and consists of inserting transversally in the striatum a thin $(0.2 \mathrm{~mm})$ dialysis tube (Amicon Vitafiber) which is then perfused with Ringer. The Ringer, flowing at a constant rate of $2 \mu \mathrm{l} / \mathrm{min}$ in the dialysis tube, extracts low molecular weight substances from the surrounding tissue by way of simple diffusion along a concentration gradient. At the distal end of the dialysis tube, the Ringer is collected every 10 to 20 min and directly injected into a high performance liquid chromatographer (HPLC) equipped with reverse phase octadecyl sulfate columns which separate DA and its metabolites, dihydroxyphenylacetic acid (DOPAC) and homovanillic acid (HVA). These substances are then quantitatively estimated by oxidative electrochemical detection. The basal output of DA is $0.3 \mathrm{pmol} / 20 \mathrm{~min}$, whereas the outputs of DOPAC and HVA are 60 and $20 \mathrm{pmol} / 20 \mathrm{~min}$, respectively. In basal conditions the output of DA, DOPAC, and HVA is stable over at least $10 \mathrm{hr}$. Histological examination of the track left by the dialysis probe in rats after $10 \mathrm{hr}$ of continuous dialysis reveals very little damage and normal neuronal morphology in the vicinity of the dialysis tube. Increase of the $\mathrm{K}^{+}$concentration in the Ringer to $30 \mathrm{~mm}$ produced a sharp, reversible increase of DA output. Both the basal and $\mathrm{K}^{+}$stimulated release were $\mathrm{Ca}^{++}$dependent, because omission of $\mathrm{Ca}^{++}$abolished basal and $\mathrm{K}^{+}$stimulated DA release. Electrical stimulation of the nigrostriatal DA neurons in the medial forebrain bundle sharply increased DA output. Amphetamine sulfate in low doses $(1.0 \mathrm{mg} / \mathrm{kg}$, i.v.) produced a 9-fold increase in DA release and decreased DOPAC and HVA output. $\alpha$-Methyl tyrosine (150 $\mathrm{mg} / \mathrm{kg}$, i.v.) reduced within $2 \mathrm{hr}$ DA release to $15 \%$ of basal values and in parallel also decreased the output of DOPAC and HVA. Reserpine $(5 \mathrm{mg} / \mathrm{kg}$, i.p.) reduced DA release but in a slower fashion than $\alpha$-methyl tyrosine and increased DOPAC and HVA. Pargyline $(75 \mathrm{mg} / \mathrm{kg}$, i.p.) produced a 4 -fold increase of DA release, while it rapidly brought to zero DOPAC and HVA output. $\gamma$ Butyrolactone $(700 \mathrm{mg} / \mathrm{kg}$, i.p.) rapidly and lastingly reduced DA, DOPAC, and HVA output. The biochemical and histological results obtained indicate that the method is suitable to estimate in the rat the changes in the release of endogenous DA and its metabolites which take place in vivo under administration of centrally acting drug.
\end{abstract}

The study of synaptic transmission in the central ncrvous system of the living animal and of the changes

${ }^{1}$ A preliminary and partial account of this work was presented at the 6th European Neuroscience Congress, Torremolinos, Spain, September $5-10,1982$ and at the 12th Annual Meeting of the Society for Neuroscience, Minneapolis, MN, October 31-November 5, 1982. This work was supported by research grants from the Assessorato alla Sanità, Regione Autonoma della Sardegna and from the Italian National Research Council (CNR). We acknowledge the award of a Training Fellowship from the European Science Foundation (Stras- induced by physiological and pharmacological conditions is of fundamental importance in the field of neuroscience. bourg, France) to A. I. spent during the period October to December 1981 at the laboratory of U. Ungerstedt, Department of Pharmacology, Karolinska, Institutet, Stockholm, Sweden. We wish to thank U. Ungerstedt for teaching us the basic technique of brain dialysis and his collaborators, A. Eliasson and A. Hallstrom, for the help provided. We acknowledge the expert technical assistance of Mr. Roberto Frau, the advice of Mr. Sandro Fenu for the histology, and the clerical work of Ms. Monika Eichenberger.

${ }^{2}$ To whom correspondence should be addressed. 
Synaptic transmission depends on the function of the presynaptic element, resulting in release of the neurotransmitter, and the responsiveness of the postsynaptic element, leading to the neurotransmitter-induced membrane changes. Various methods have been described to study in vivo the release of neurotransmitters. For what concerns dopamine (DA), the available methods estimate the endogenous amine or the labeled DA exogenously administered or synthetized endogenously from labeled tyrosine in superfusates of the ventricular system (Tilson and Sparber, 1972; Chiueh and Moore, 1973, 1974, 1975), of the exposed surface of the caudate (Besson et al., 1969a, b, 1971, 1973; Gauchy et al., 1974), or of specific dopaminergic areas through stereotaxically placed pushpull cannulae (Gaddum, 1961; McLennan, 1964; Szerb, 1967; McKenzie and Szerb, 1968; Myers, 1970, 1972; Riddell and Szerb, 1971; Lloyd and Bartholini, 1975; Stadler et al., 1975; Nieoullon et al., 1977; Philippu et al., 1980; Elghozi et al., 1981). The advantages and disadvantages of these techniques have already been discussed (Chase and Kopin, 1968; Vogt, 1969; Chiueh and Moore, 1974; Yaksh and Yamamura, 1974; Nieoullon et al., 1977), but it is readily apparent that the push-pull cannula offers substantial advantages over other techniques. As a matter of fact, the push-pull cannula is the most generally adopted method for estimating in vivo the release of neurotransmitters and in particular of $\mathrm{D} \Lambda$.

However, this method is not free from limitations, the most critical one being that of the tissue damage it produces (Chase and Kopin, 1968; Tilson and Sparber, 1972; Chiueh and Moore, 1974; Nieoullon et al., 1977). This is due not only to the size of the push-pull cannula (e.g., $1.0 \mathrm{~mm}$ outer diameter; Nieoullon et al., 1977) but also, and particularly, to the physical impact of the superfusion fluid flowing at high rates (e.g., $33 \mu \mathrm{l} / \mathrm{min}$; Nieoullon et al., 1977) on the nervous tissue at the tip of the cannula. Although the damage at the tip has been reduced in later modifications of the technique (Myers, 1970; Nieoullon et al., 1977), such disadvantage is inherent to the "open" characteristic of the system which involves direct contact of the superfusion fluid with the nervous tissue. This "open" feature also limits the reduction of the cannula diameter since this would geometrically increase the pressure required to maintain an adequate flow and consequently increase the degree of tissue damage at the tip of the cannula. As a matter of fact, the push-pull cannula technique has been applied most often to larger animals like cats and monkeys and less often to rats (McLennan, 1964; McKenzie and Szerb, 1968; Myers, 1970; Lloyd and Bartholini, 1975; Nieoullon et al., 1977).

A second problem in the estimation of the in vivo release of DA derives from the low levels of the amines recovered in basal conditions; for this reason most of the techniques estimating the release of DA in vivo do not involve the measurement of the endogenous unlabeled amine but rather that of labeled DA previously taken up (Von Voigtlander and Moore, 1973) or synthetized from radioactive tyrosine (Besson et al., 1969a, b, 1971, 1973; Riddell and Szerb, 1971; Tilson and Sparber, 1972; Chiueh and Moore, 1973, 1974, 1975). Classic fluorimetric procedures are not sensitive enough to measure the output of unlabeled DA under basal conditions (Por- tig and Vogt, 1966; McKenzie and Szerb, 1968; Roth et al., 1969), and, in the few studies where endogenous DA has been measured, a time-consuming radioenzymatic procedure has been employed (Lloyd and Bartholini, 1975; Stadler et al., 1975; Philippu et al., 1980).

A recent and entirely different methodology which has been proposed to estimate in vivo the release of endogenous DA and metabolites is the voltammetry through carbon-fiber electrodes (Wightman et al., 1976, 1978; Conti et al., 1978; Cheng et al., 1979; Ewing et al., 1982). This technique is very promising, but its ability to detect endogenous DA in untreated animals is uncertain at the moment (Gonon et al., 1980). From these considerations it appears that there is still the necessity of a method for the study of the in vivo release of DA which would estimate by a rigorous, sensitive, and simple analytical procedure the endogenous, unlabeled amine and/or its metabolites and which would be routinely applicable to the rat, a species where most of the studies on DA transmission have been performed. In this report we describe a method which in part meets the above requirements.

This method involves a closed system in which a thin dialysis tube ( $0.2 \mathrm{~mm}$ outer diameter) is inserted through the striata, and it is based on the principle that the perfusion fluid, which flows inside the dialysis tube, extracts low molecular weight substances from the surrounding tissue along a concentration gradient. This method, developed by Ungerstedt and collaborators (1982) and others (Hernandez et al., 1983; Johnson and Justice, 1983), has been coupled by us to reverse phase high performance liquid chromatography (HPLC) with electrochemical detection (Refshauge et al., 1974; Felice et al., 1978; Mefford, 1981). This technique permits the accurate estimation of the basal output of endogenous DA and metabolites from rat striatum, its basic characteristics, and the changes induced by drugs.

\section{Materials and Methods}

Reagents and drugs. Reagents were analytical grade and some (methyl alcohol) specially prepared for HPLC. Double-distilled water was used. All solutions were filtered in a whole glass filtering apparatus through Millipore glass fiber filters, type GS $0.22 \mu \mathrm{m}$ (Millipore, S.A., Morsheim, France). The following drugs were used: amphetamine sulfate, pargyline hydrochloride, reserpine metanesulfonate, $\gamma$-butyrolactone (Sigma), and $\alpha$ methyl $p$-tyrosine methyl ester hydrochloride. All drugs except reserpine were administered dissolved in saline. Reserpine was administered intraperitoneally dissolved in a small volume of glacial acetic acid which was diluted with water and the $\mathrm{pH}$ brought to about 5.0 with $\mathrm{NaOH}$.

Dialysis procedure. Male Sprague-Dawley rats (180 to $200 \mathrm{gm}$ ) were anesthetized with a 1.5 to $2.0 \%$ halothaneoxygen mixture and mounted on a David Kopf stereotaxic apparatus. During the whole procedure body temperature was monitored by a rectal probe and automatically adjusted to $37^{\circ} \mathrm{C}$ through a Harvard Homeotermic Blanket system (Harvard Apparatus Comp., Pleasant, MA). Blood pressure and cardiac frequency were monitored through a cannula inserted in the femoral artery. One hole was drilled on each side of the temporal bone at the level of the head of the caudate nucleus (coordi- 
nates A 7.4, V 5.5 from temporal bone) according to Konig and Klippel (1963). After excision of the dura on each side, a previously prepared acrylic copolymer dialysis tube with a cutoff of $M_{\mathrm{r}}=50,000$ (Vita Fiber Type $3 \times 50$, Amicon Corp., Lexington, MA), bearing a tungsten wire (diameter $0.15 \mathrm{~mm}$ ) inside, was fastened in a transverse position to a stereotaxic holder mounted on the right bar of the stereotaxic apparatus. The dialysis tube had its surface previously glued with Super-Epoxy resin, except for two zones, $4.0 \mathrm{~mm}$ wide, separated by a central zone $2 \mathrm{~mm}$ wide also covered by Super-Epoxy. The dialysis tube-tungsten wire assembly was pushed by operating the right manipulator until its end appeared in the opposite hole of the cranium; this end was then pulled by operating the left holder. Pulling was stopped when the tube was positioned according to reference points labeled on the tube and calculated so that each of the two nonglued portions of the dialysis tube would correspond to the caudate head on each side. Figure 1 shows schematically the position of the dialysis tube in the caudate. Subsequently the dialysis tube was connected with one end to a polyethylene tube $(2 \mathrm{~mm}$ outer diameter) attached to a 1-ml Hamilton syringe filled with Ringer placed on a Harvard perfusion apparatus. The composition of the Ringer was the following: $\mathrm{NaCl}, 147.2$ $\mathrm{mM} ; \mathrm{CaCl}_{2}, 3.4 \mathrm{mM}$ KCl, $4.0 \mathrm{mM}$ (pH 5.9 to 6.1 ). At this point the tungsten wire was extracted from the dialysis tube, and perfusion at a constant flow of $2 \mu \mathrm{l} / \mathrm{min}$ was started. Every 10 to $20 \mathrm{~min}$ a 20 - to $40-\mu \mathrm{l}$ portion of the Ringer was collected from the other end of the dialysis tube in a mini-vial containing $10 \mu \mathrm{l}$ of $0.1 \mathrm{~N}$ perchloric acid. An aliquot of each fraction (25 or $45 \mu \mathrm{l}$ ) was immediately and directly injected into an HPLC apparatus to analyze it quantitatively for $\mathrm{DA}$ and its acid metabolites, dihydroxyphenylacetic acid (DOPAC) and homovanillic acid (HVA).

Analytical procedure. The dialysate was injected into the HPLC through a Rheodyne 7125 valve (Rheodyne Inc., Cotati, CA) equipped with a 100- $\mu$ l loop. The flow was maintained at $2 \mathrm{ml} / \mathrm{min}$ through a dual piston $\mathrm{M}-45$ pump (Waters Associates, Milford, MA) working at a pressure of about 2000 to 3000 psi. Pressure pulses were dampened by a PD-2 pulse damper (Bioanalytical System, West Lafayette, IN). The separation of DA, DOPAC, and HVA was achieved by reverse phase columns

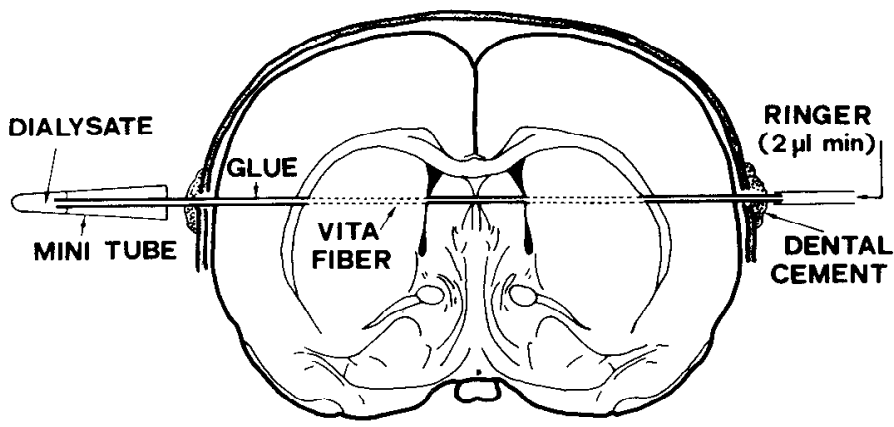

Figure 1. Schematic drawing of the trans-striatal dialysis technique. The drawing shows a frontal section of rat brain according to the atlas of Konig and Klippel (1963) (level A 7470 ) and the tranversally inserted dialysis tube. Note that the tube is covered with Super-Epoxy in its extrastriatal portions. (length $250 \mathrm{~mm}$, inner diameter $4.6 \mathrm{~mm}$ ) prepacked with deactivated octadecyl silica particles of $5 \mu \mathrm{m}$ (Supelcosil LC-18-DB; Supelco Inc., Bellefonte, PA) using a mobile phase of $0.23 \mathrm{M}$ sodium acetate, $0.015 \mathrm{M}$ citric acid, and $100 \mathrm{mg}$ /liter of EDTA, pH 5.5. We routinely used a guard column (Pellicular guard column LC-18, Supelco) to prevent deterioration and plugging of the analytical column. DA, DOPAC, and HVA were measured by electrochemical detection using a LC-4B amperometric controller (Bioanalytical System). The flow cell was equipped with a silicon carbon paste TL-3 working electrode (Bioanalytical System) and an $\mathrm{Ag} / \mathrm{AgCl}$ reference electrode. The potential was set at $+0.65 \mathrm{~V}$ (oxidation mode;. Signals were recorded on a two-pen Omniscribe recorder (Houston, Austin, TX). Since DOPAC and HVA were 100 to 200 times more concentrated than DA, in order to avoid saturation of the signal, the sensitivity of the detector-recorder system had to be increased by a factor of 100 to 250 when passing from the DOPAC peak to the DA peak and decreased by a factor of 100 when passing from the DA peak to the HVA peak. In some experiments, to verify the identity of the peaks obtained, a dual parallel electrode (Bioanalytical System) was used.

Other experimental procedures. In some experiments the composition of the Ringer was varied. When high $\mathrm{K}^{+}$ was used, the $\mathrm{KCl}$ of the Ringer was brought to $30 \mathrm{mM}$, while the $\mathrm{NaCl}$ was reduced from $147.2 \mathrm{mM}$ to $117.2 \mathrm{mM}$. When $\mathrm{CaCl}_{2}$ was omitted, $\mathrm{NaCl}$ was increased to 150.6 mM. In some experiments the medial forebrain bundle (MFB) (coordinates, A-1 from bregma, L 1.6; V-7.2, from dura mater) was electrically stimulated for $10 \mathrm{~min}$ using bipolar electrodes insulated except at the tip. The stimulus consisted of square wave pulses with the following parameters: $1 \mathrm{msec}, 0.1 \mathrm{~mA}, 0.5$ to $20 \mathrm{~Hz}$. At the end of each experiment the rat was perfused with formalin and the site of the dialysis tube was verified histologically after Luxol fast blue-cresyl violet stain.

Statistics. Basal release showed little variation from rat to rat provided that the tube was correctly placed in the same zone of the caudate; therefore, it was not necessary to calculate the changes induced by the treatments as percentage of the basal values obtained in each individual animal. Thus, after calculating all the results as picomoles per sample, we compared for each experimental group the basal values obtained in the last three samples of stabilized release (the zero time values) to the values obtained at each time after the treatments. The significance was estimated by the Student's $t$ test. However, to facilitate the graphical representation of the results, the mean picomoles $\pm \mathrm{SEM}$ were converted to percentage \pm SEM of the values of stabilized release (zero time values).

\section{Results}

Analytical procedure. The relationship between the amount of DA, DOPAC, and HVA injected into the HPLC and the response measured from the height of the corresponding peaks was linear from 0.02 to $100 \mathrm{pmol}$ for DA and from 0.1 to 500 pmol for DOPAC and HVA. The sensitivity of the method, estimated from the amount of the compound which gives a peak height three times higher than the baseline noise, is about $0.02 \mathrm{pmol}$ 
for DA and 0.1 pmol for DOPAC and HVA. This sensitivity is 10 to 60 times higher than the mean basal values of DA, DOPAC, and HVA (see below) found in the sample of dialysate $(40 \mu \mathrm{l})$ routinely injected in the HPLC.

Figure 2 shows a chromatogram of a 20 -min sample of dialysate taken under basal conditions. At the lowest sensitivity, uric acid, DOPAC, HVA, and 5-hydroxyindolacetic (HIAA) can be detected. At the higher sensitivity DA is detected. The identity of the substances present in the dialysate with that of reference compounds was based on the following criteria: (1) identity of the retention time; (2) co-elution; (3) identity of the electrochemical behavior as indicated by the identity of the ratio between the electrochemical responses of the endogenous and exogenous compounds at two different potentials.

Table I shows the ratio of the detector response obtained by analyzing the endogenous compounds and standards of DA, DOPAC, and HVA at two different potentials. Clearly, the ratio is identical for the endogenous and the standard compounds.

Basal release. Figure 3 shows the time course over 10 $\mathrm{hr}$ of the basal release of DA, DOPAC, and HVA in 20min samples. It will be noticed that the output of DA tends to decrease during the first hour, so that by $2 \mathrm{hr}$ it reaches a constant value of about 0.3 pmol every $20 \mathrm{~min}$
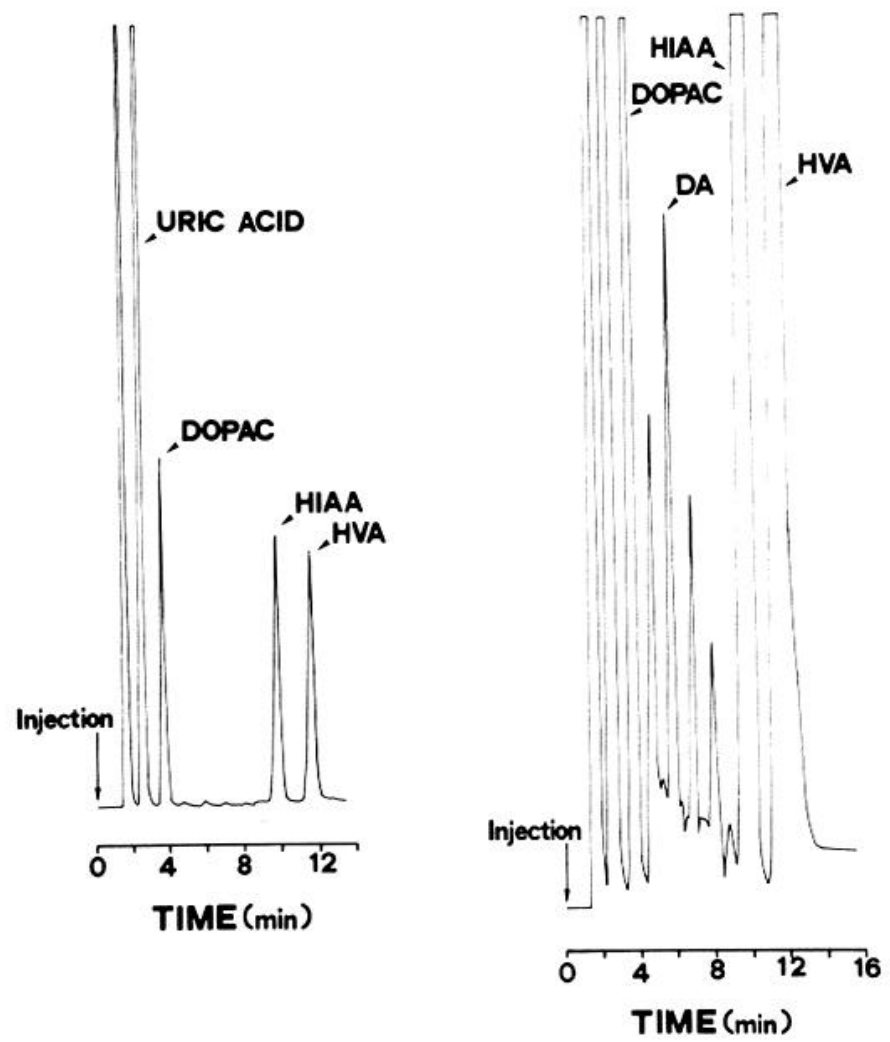

Figure 2. Chromatogram of $40 \mu \mathrm{l}$ of dialysate (20-min sample) mixed with $5.0 \mu \mathrm{l}$ of $0.1 \mathrm{~N} \mathrm{HClO}_{4}$. On the left is the tracing obtained at the lowest sensitivity on the two-pen recorder showing the peaks of DOPAC (58 pmol, $50 \mathrm{nA}$ full scale), 5hydroxyindolacetic acid (HIAA) (60 pmol, $20 \mathrm{nA}$ full scale), and HVA (25 pmol, $20 \mathrm{nA}$ full scale). On the right is the tracing obtained at the highest sensitivity showing the peak of DA (0.25 pmol, $0.2 \mathrm{nA}$ full scale).
TABLE I

Comparison of ratios for parallel outputs at $0.65 \mathrm{~V}$ and $0.80 \mathrm{~V}$ for standard and dialysate HPLC injections

Conditions of the HPLC were the same as described in the text except for the potentials at the dual parallel electrode.

\begin{tabular}{llcc}
\hline Standard & DA & DOPAC & HVA \\
Ratio & 0.81 & 0.78 & 0.30 \\
Amount & 0.38 & 82 & 34 \\
$\quad$ (pmol) & & & \\
Sample & & & \\
Ratio & 0.83 & 0.80 & 0.29 \\
Amount & 0.30 & 68 & 25 \\
\hline
\end{tabular}

$(0.285 \pm 0.017 \mathrm{pmol}$, mean $\pm \mathrm{SEM}$ of eight experiments $)$ which is maintained for at least $10 \mathrm{hr}$. In contrast, DOPAC and HVA outputs tend to increase during the first hour after implantation, and after $2 \mathrm{hr}$ they reach a constant level of $62.2 \pm 0.4$ and $23.5 \pm 0.18 \mathrm{pmol} / 20 \mathrm{~min}$ (mean \pm SEM of eight experiments), respectively. It is notable that the output of DOPAC and HVA is 100 to 200 times that of DA. In view of the observation that the output of DA, DOPAC, and HVA reached a plateau after about $2 \mathrm{hr}$ from the start of the dialysis, pharmacological, chemical, or physical treatments were applied only after this interval and in any case only when in three subsequent 20-min samples a constant output of DA, DOPAC, and HVA was obtained. In contrast with studies in cats using push-pull cannulae and measuring the labeled DA synthesized from labeled tyrosine (Nieoullon et al., 1977), basal DA, DOPAC, and HVA outputs were quite independent from spontaneous physiological changes of arterial blood pressure and heart rate.

Histology. Figure 4 shows pictures at different magnification of a sagittal section of the caudate of a rat implanted for $10 \mathrm{hr}$ with a dialysis tube continuously perfused with Ringer and fixed by formalin perfusion while dialysis was carried out. The degree of local trauma appears rather small as judged from the normal appearance of neurons and myelinated bundles in the immediate vicinity of the track left by the dialysis tube and by the absence of blood around it.

$\mathrm{K}^{+}$-evoked release. As shown in Figure 5 the depolarizing agent $\mathrm{K}^{+}(30 \mathrm{mM})$ produced a sharp increase of DA output when added for $20 \mathrm{~min}$ to the Ringer. The output of DA rapidly returned to basal levels when normal Ringer was reintroduced.

Calcium dependency. Calcium dependency is considered to be a prerequisite of exocytotic neurotransmitter release (Rubin, 1970). As shown in Figure 6, omission of the $\mathrm{Ca}^{++}$from the Ringer and its replacement with $\mathrm{Na}^{+}$ resulted in a rapid fall of DA output to unmeasurable levels. Application of $30 \mathrm{mM} \mathrm{KCl}$, in the absence of $\mathrm{Ca}^{++}$, failed to stimulate DA release. Reintroduction of the normal Ringer rapidly returned DA release to basal values.

Electrical stimulation of nigrostriatal DA neurons. As shown in Figure 7, electrical stimulation of nigrostriatal axons along their course in the MFB significantly increased the output of DA in a manner related to the intensity of the applied stimulus; with stimuli of $20 \mathrm{~Hz}$, DA release maximally increases by more than six times the basal values. 


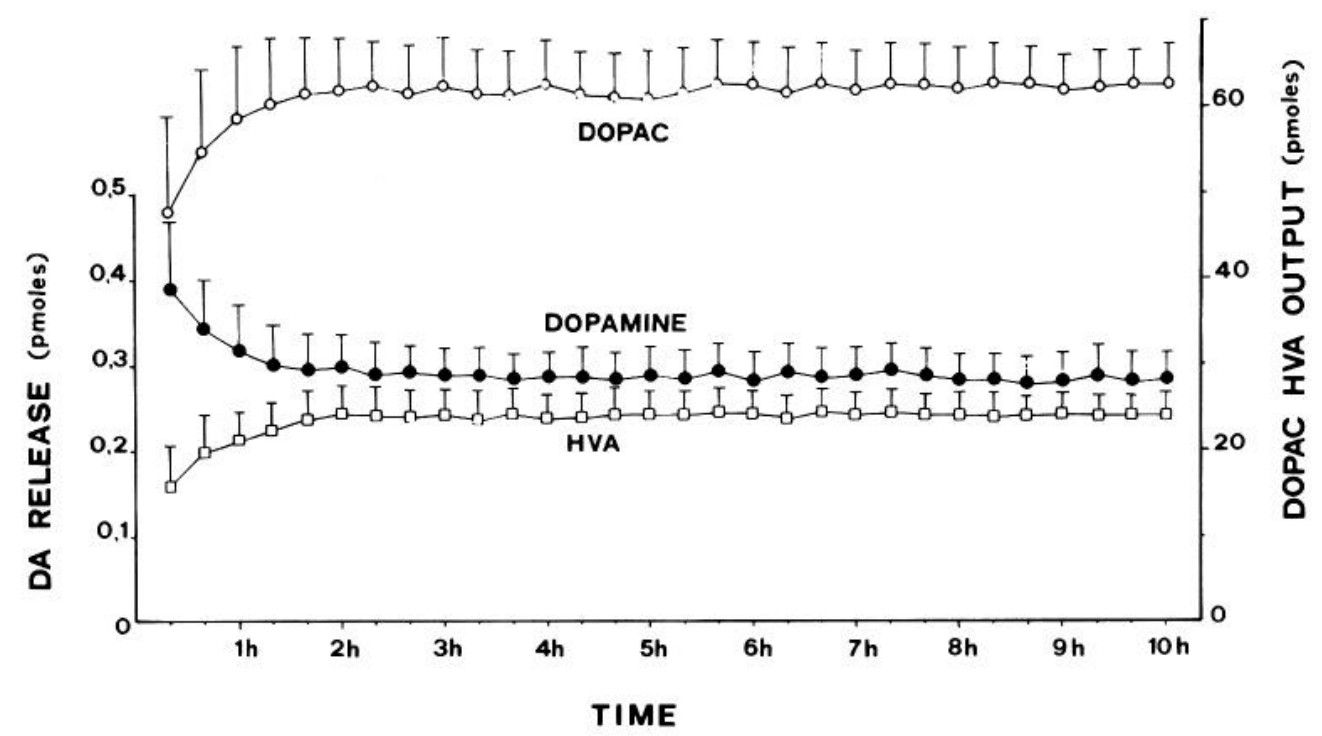

Figure 3. Time course of the basal output of DA, DOPAC, and HVA. Values are means $\pm \mathrm{SEM}$ of the results obtained in five rats.
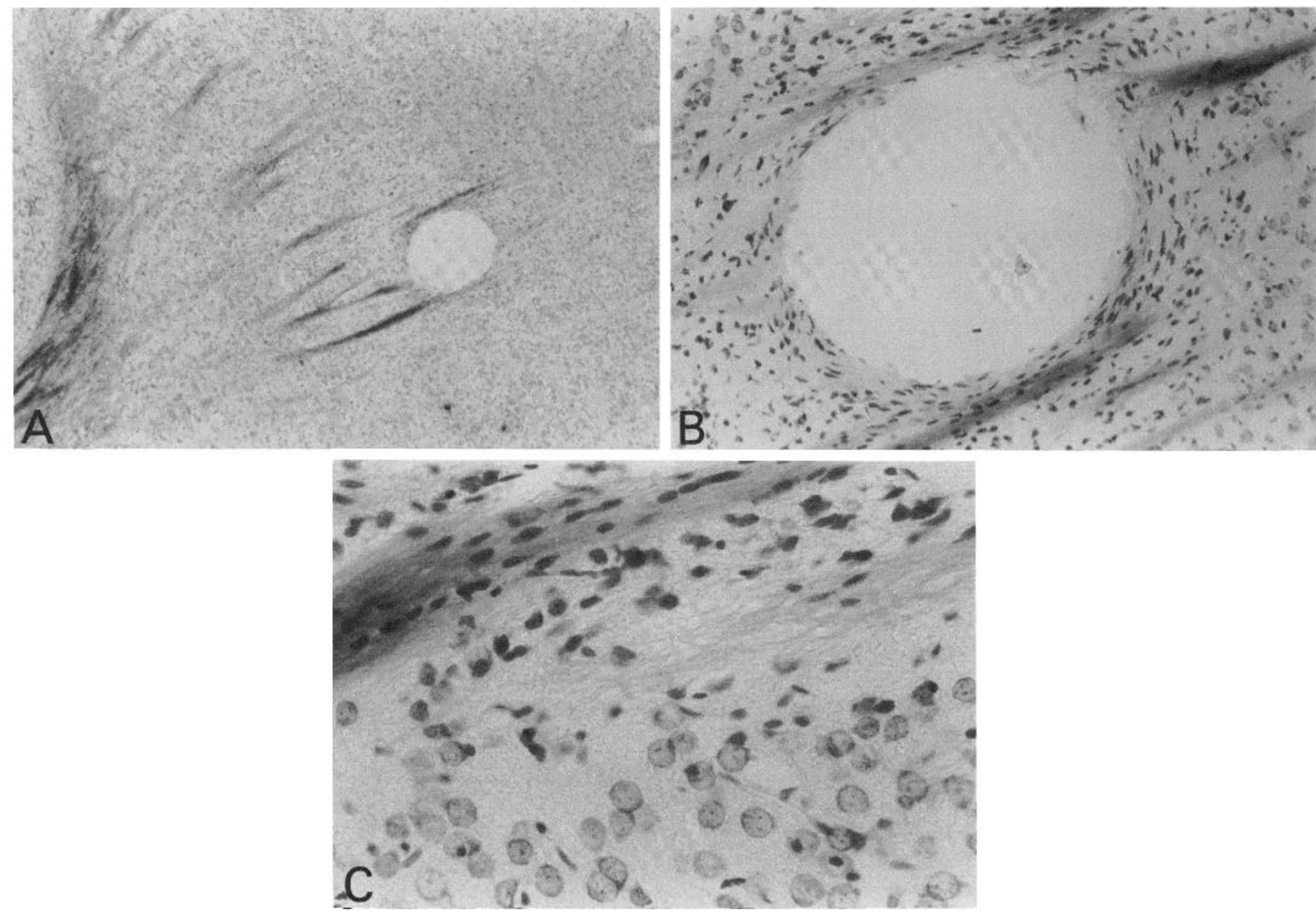

Figure 4. Histological pictures of sagittal sections through the caudate of a rat implanted with the dialysis tube, kept under continuous dialysis for $10 \mathrm{hr}$, and killed by intracardiac formalin perfusion-fixation during the dialytic perfusion. Luxol fast blue-cresyl violet stain. $A$, Low magnification $(\times 30)$ of the caudate and of the track left by the dialysis tube. Note its circular section and the lack of distortions and major alterations of the surrounding nervous tissue. $B$ and $C$, Higher magnifications $(\times$ 125 and $\times 300$ ) of $A$ showing the intactness of myelinated bundles adjacent to the track, the absence of blood extravasation, and the normal neuronal morphology around the track, except for a thin zone of neuronal pyknosis in its immediate vicinity. 


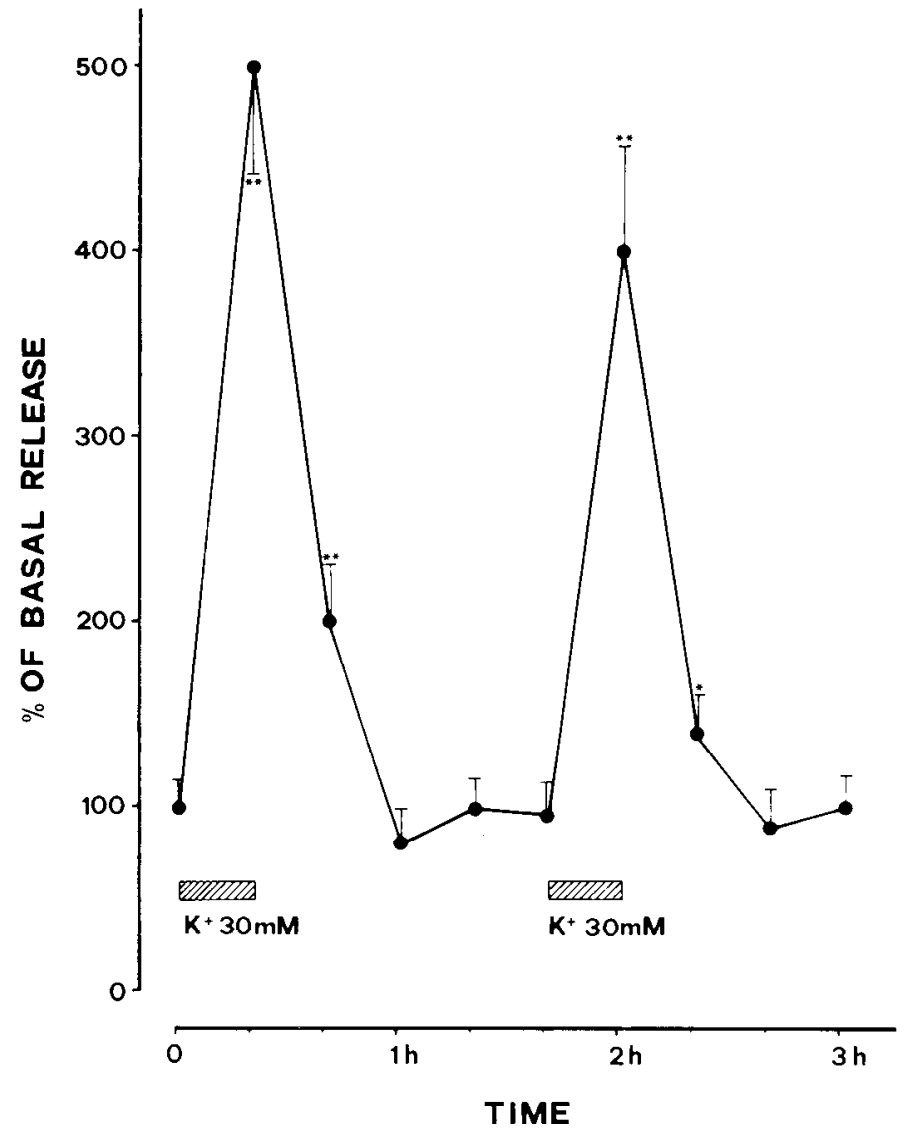

Figure 5. Effect of perfusion with a Ringer containing $30 \mathrm{~mm}$ $\mathrm{K}^{+}$on DA output. Results are means \pm SEM of four experiments. Basal output of DA was $0.27 \pm 0.015 \mathrm{pmol} / 20 \mathrm{~min}$ (mean \pm SEM of the zero time values obtained in the four experiments). *, $p<0.05 ; * *, p<0.001$ with respect to basal values.

Systemic administration of drugs interfering with $D A$ transmission. Five classic drugs known to interfere by known mechanisms with DA transmission were tested for their effects on the output of DA and metabolites. These drugs were amphetamine, which is thought to release DA (Carlsson et al., 1966; Glowinski et al., 1966; Besson et al., 1969a, 1971; Chiueh and Moore, 1973, 1974, 1975; Arnold et al., 1977); $\alpha$-methyl tyrosine ( $\alpha$ MT), which blocks competitively the rate-limiting step of DA biosynthesis, i.e. the enzyme tyrosine-hydroxylase (Nagatsu et al., 1964; Spector et al., 1965; Weissman and Koe, 1965; Rech et al., 1966); reserpine, which inactivates the granular storage mechanism of DA (Euler and Lishajko, 1963; Andén et al., 1964; Glowinski et al., 1966; Guldberg and Broch, 1971); pargyline, an irreversible inhibitor of monoaminoxidase (MAO), the enzyme which catabolizes DA intraneuronally (Kopin, 1964); and $\gamma$ butyrolactone $(\gamma$-BL) the precursor of $\gamma$-hydroxybutyrate, a drug which blocks the firing activity of DA neurons (Walters and Roth, 1972, 1974; Walters et al., 1973).

As shown in Figure 8, amphetamine sulfate $(1.0 \mathrm{mg} /$ $\mathrm{kg}$, i.v.) sharply increased the output of DA while it reduced DOPAC and, after a delay of $40 \mathrm{~min}$, also HVA. The release of DA was maximally increased by 9 times the basal values already in the first 20 -min sample, then rapidly decreased returning to basal values within $2 \mathrm{hr}$;
DOPAC and HVA decreased by about 75 and $40 \%$, respectively, and remained at these values to the end of the experiment.

$\alpha$-MT (150 mg/kg, i.v.) produced, as shown in Figure 9 , an immediate fall of DA release, which, after $1 \mathrm{hr} 20$ min, was already reduced by more than $80 \%$ and remained at these low levels for the duration of the experiment ( $3 \mathrm{hr}$ ). DOPAC and HVA also decreased but with a delay from DA of $20 \mathrm{~min}$ and $1 \mathrm{hr}$, respectively. DOPAC was decreased by more than $80 \%$ at $1 \mathrm{hr} 40 \mathrm{~min}$, and HVA took $2 \mathrm{hr}$ and $20 \mathrm{~min}$ to be reduced by the same degree. Again, the changes of HVA paralleled those of DOPAC but developed more slowly.

As shown in Figure 10, reserpine (5 mg/kg, i.p.) steadily reduced DA release. DA release was reduced significantly $(-40 \%)$ already 40 min after administration. Four hours after administration, the release was reduced by about $80 \%$ and remained at these levels to the end of the experiment $(6 \mathrm{hr})$. DOPAC and HVA showed a rapid increase, peaking at $1 \mathrm{hr}(63 \%)$ and at $1 \mathrm{hr} 40 \mathrm{~min}(71 \%)$, respectively; returned to basal values at about $2 \mathrm{hr}$ and $4 \mathrm{hr}$, respectively; and then steadily decreased. The decrease was about $50 \%$ for DOPAC at $4 \mathrm{hr}$ postdrug and about $25 \%$ for HVA at $6 \mathrm{hr}$. Therefore, the time course of these metabolites can be described as an early increase followed by a slow steady decrease.

Pargyline administration ( $75 \mathrm{mg} / \mathrm{kg}$, i.p.) resulted, as shown in Figure 11, in a steady increase of DA release reaching within $1 \mathrm{hr} 40 \mathrm{~min}$ a plateau of about 5 times the basal release. Such high level of DA release was maintained to the end of the experiments $(3 \mathrm{hr}$ ). DOPAC showed a sharp decrease, falling by $40 \mathrm{~min}$ to about $50 \%$ the basal values and in $1 \mathrm{hr} 40 \mathrm{~min}$ to less than $1 \%$. HVA started to decrease after a delay of $1 \mathrm{hr}$, and its fall roughly paralleled that of DOPAC.

Administration of reserpine $(5 \mathrm{mg} / \mathrm{kg}$, i.p.) $4 \mathrm{hr}$ after pargyline $(75 \mathrm{mg} / \mathrm{kg}$, i.p.) resulted, as shown in Figure 12 , in a sharp increase of DA release, reaching within 40 min values 3 times those under pargyline alone. Thereafter, DA release slowly decreased and set at a plateau

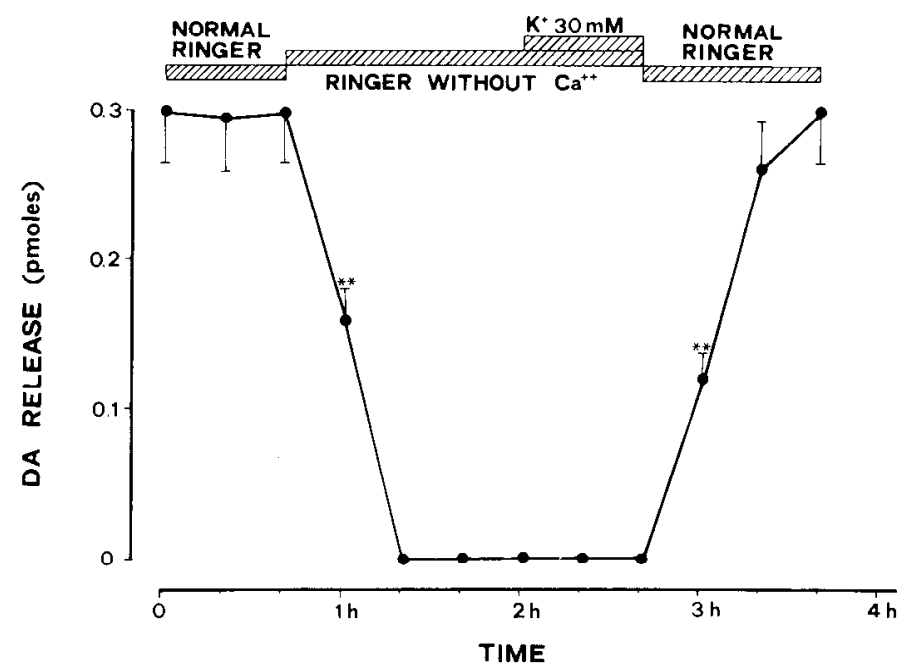

Figure 6. Effect of the omission of $\mathrm{Ca}^{++}$on the basal and $\mathrm{K}^{+}$-stimulated DA output. Results are means $\pm \mathrm{SEM}$ of three experiments. $* *, p<0.001$ with respect to basal values. 


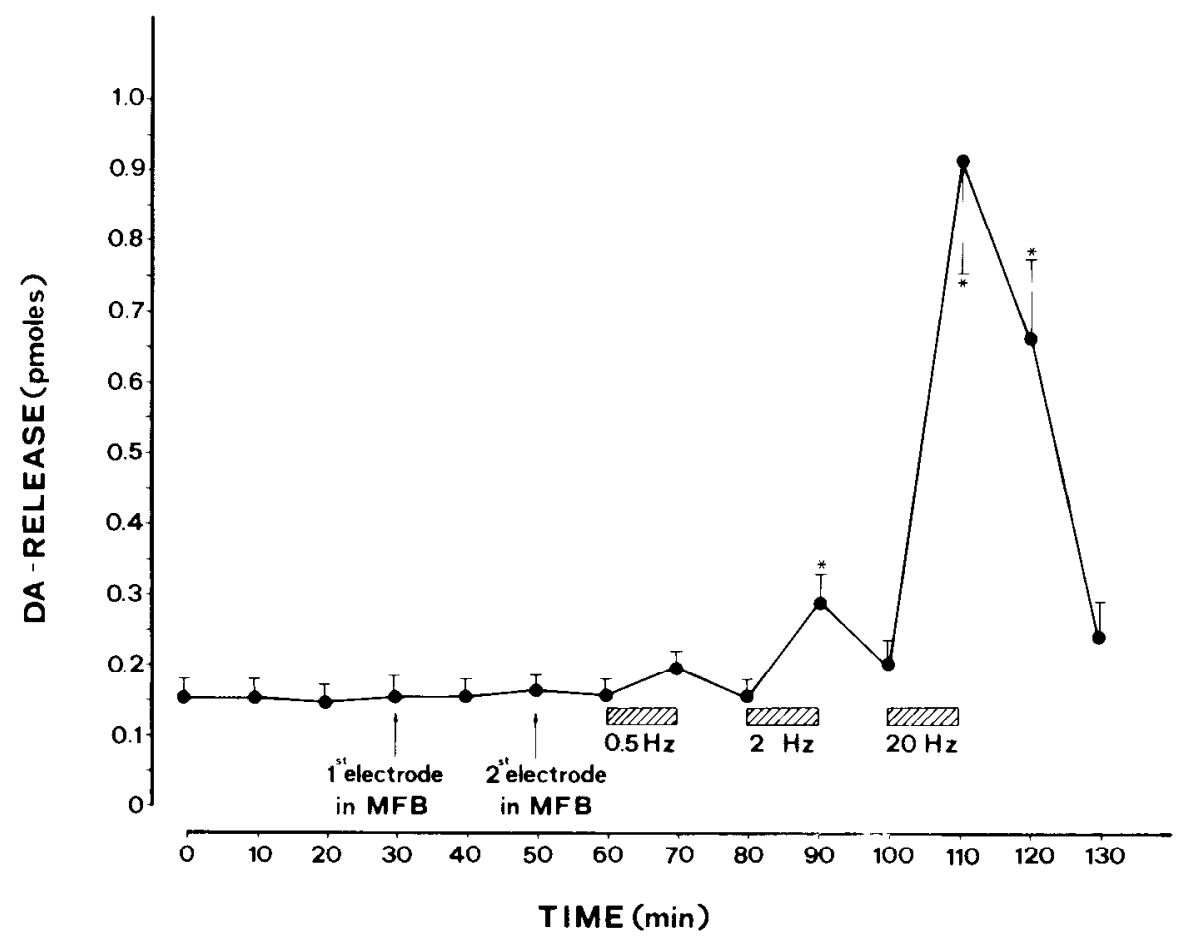

Figure 7. Effect of electrical stimulation of the medial forebrain bundle on DA output. Results are means $\pm \mathrm{SEM}$ of four experiments. $*, p<0.05$ with respect to basal values.

of about twice the levels under pargyline alone for the subsequent $2 \mathrm{hr}$; DOPAC and HVA remained down to levels of less than $1 \%$ the basal ones in spite of reserpine administration.

$\gamma$-Butyrolactone $(700 \mathrm{mg} / \mathrm{kg}$, i.p.) produced, as shown in Figure 13, a sharp drop of DA release $(-70 \%$ after the first $20 \mathrm{~min}$ ), which, after $1 \mathrm{hr} 40 \mathrm{~min}$ and up to $5 \mathrm{hr}$, remained down to values lower than the basal ones. Thereafter, DA release slowly returned toward basal values but $8 \mathrm{hr}$ postdrug was still significantly lower than the basal levels. After a delay of $20 \mathrm{~min}$, DOPAC and HVA dropped in parallel with DA. DOPAC decreased more than HVA, but at $3 \mathrm{hr}$ both acids had plateaued to levels 70 to $80 \%$ lower than the basal ones. Between $4 \mathrm{hr}$ and $5 \mathrm{hr}$, both acids started to return slowly toward normal values with DOPAC being faster than HVA in this trend. Between $5 \mathrm{hr}$ and $5 \mathrm{hr} 20 \mathrm{~min}$, DOPAC surpassed basal values and significantly increased, peaking at $6 \mathrm{hr}$, and then returned to basal values at about 7 hr. HVA showed a similar behavior, reaching within $6 \mathrm{hr}$ $20 \mathrm{~min}$, values significantly higher than the basal ones and returning to the basal values at $7 \mathrm{hr} 40 \mathrm{~min}$. Therefore, the time course of the acids can be described as biphasic with an early and long-lasting decrease parallel to the drop of DA release and a secondary increase over basal values coincident with the reappearance of DA release.

\section{Discussion}

Three basic characteristics of the method here described to estimate in vivo DA release are worth emphasis. (1) The collecting probe, i.e., the dialysis tube, has a diameter of only $0.2 \mathrm{~mm}$, i.e., 5 to 10 times smaller than that of most push-pull cannulae (Myers, 1970; Nieoullon et al., 1977). This feature is expected to reduce the degree of local trauma produced by the system. (2) The system is a closed one. This feature, by avoiding direct contact of the perfusing fluid with the tissue, is expected to reduce to a minimum the local damage produced by the perfusion fluid. This expectation is confirmed by the histology of the track left by the dialysis tube after $10 \mathrm{hr}$ of perfusion showing normal tissue organization and neuronal morphology along it and in its vicinity. (3) The system provides very constant and reproducible basal values of output of DA and of its acid metabolites.

The values of basal DA output obtained by us (about $2 \mathrm{pg} / \mathrm{min}$ ), while agreeing with those of Ungherstedt and colleagues (1982), are about 50 times lower than those reported by Hernandez et al. (1983) (about $100 \mathrm{pg} / \mathrm{min}$ ). The reason for this discrepancy is unclear at the moment but might be related to the fact that different conditions and materials have been used.

The present technique appears suitable to recover and detect endogenous unlabeled DA, DOPAC, and HVA arising from the striatum of a living rat. The basic process which continuously and steadily provides DA to the dialysate appears to have the characteristics of an exocytotic release mechanism which can be affected by depolarization of the terminal. In fact, the basal output of DA is, like exocytotic release (Rubin, 1970), calcium dependent since it is abolished by omission of calcium from the Ringer and can be stimulated by the local application of depolarizing concentrations of $\mathrm{K}^{+}$. The output of DA appears dependent on the activity of the nigrostriatal DA system because electrical stimulation of the nigrostriatal neurons along their course in the MFB (Andén et al., 1966) stimulates it. Moreover, an agent such as $\gamma$-BL, known to block the firing of DA neurons 

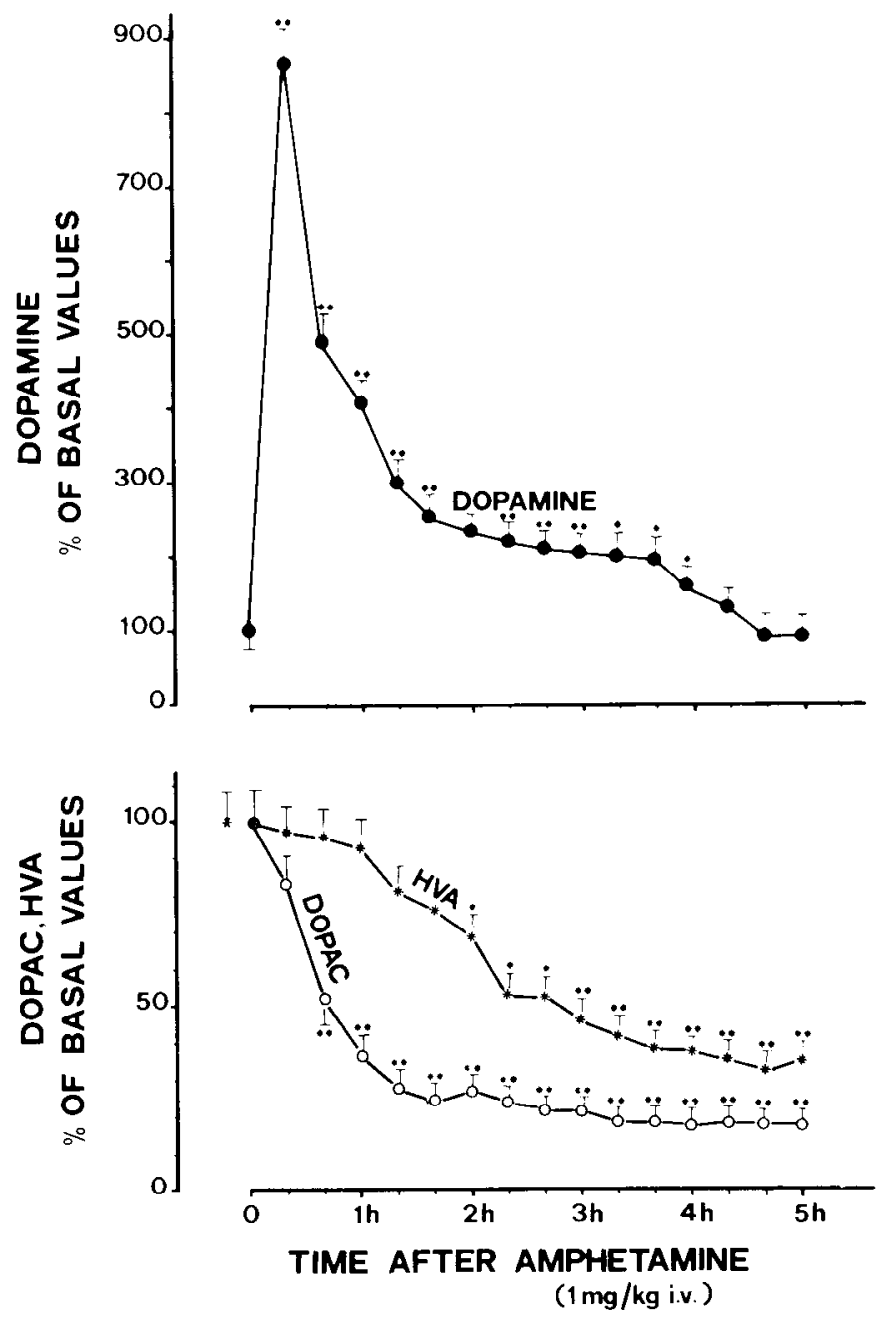

Figure 8. Effect of amphetamine sulfate $(1 \mathrm{mg} / \mathrm{kg}$, i.v.) on DA, DOPAC, and HVA outputs. Results are means \pm SEM of three experiments. Basal outputs were as follows: DA, $0.31 \pm$ 0.017 ; DOPAC, $65 \pm 4.5$; HVA, $25 \pm 1.8 \mathrm{pmol} / 20 \mathrm{~min}$ (mean \pm SEM). $*, p<0.05 ; * *, p<0.001$ with respect to basal values.

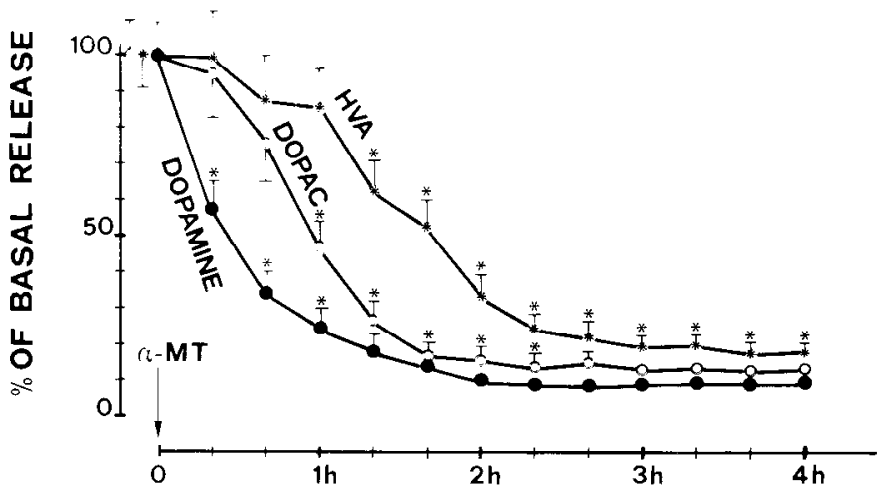

TIME AFTER $\alpha$-METHYLTYROSINE

(150 mg/kg i.v.)

Figure 9. Effect of $\alpha$-methyltyrosine $(\alpha-M T)$ methyl ester hydrochloride ( $150 \mathrm{mg} / \mathrm{kg}$, i.v.) on the outputs of DA, DOPAC, and HVA. Results are means \pm SEM of five experiments. Basal outputs were as follows: DA, $0.27 \pm 0.012$; DOPAC, $58 \pm 3.0$ HVA, $21 \pm 1.1 \mathrm{pmol} / 20 \mathrm{~min}$ (mean $\pm \mathrm{SEM}$ ). $*, p<0.05$ with respect to basal values.

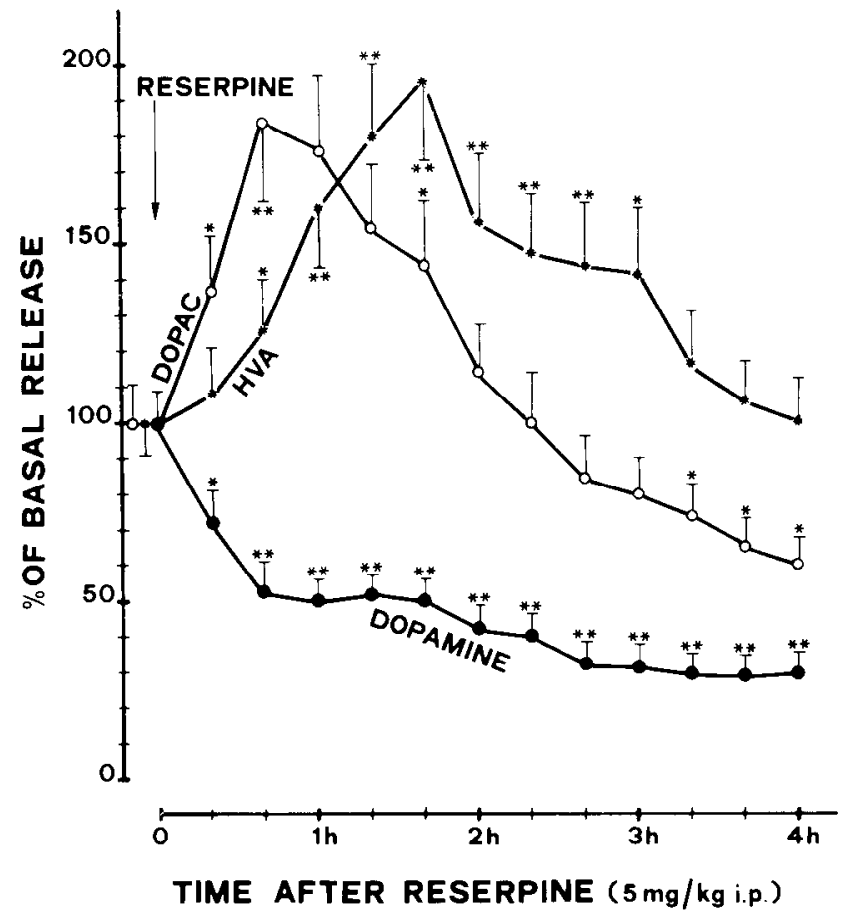

Figure 10. Effect of reserpine methanesulfonate $(50 \mathrm{mg} / \mathrm{kg}$, i.p.) on the outputs of DA, DOPAC, and HVA. Results are means \pm SEM of four experiments. Basal outputs were as follows: DA, $0.32 \pm 0.018$; DOPAC, $63 \pm 4.2$; HVA, $25 \pm 1.7$ $\mathrm{pmol} / 20 \mathrm{~min}($ mean $\pm \mathrm{SEM}) . *, p<0.05 ; * *, p<0.001$ with respect to basal values.

(Walters and Roth, 1972, 1974; Walters et al., 1973), dose dependently and drastically reduced the output of DA and of its metabolites. The output of DA and of its metabolites was critically dependent on the synthesis of DA, as administration of $\alpha$-MT (Spector et al., 1965; Rech et al., 1966) rapidly and markedly reduced the output of DA and of its metabolites in the dialysates. The output of DA is also dependent upon the integrity or the function of certain presynaptic processes which are essential for the compartmentalization or metabolism of DA. Thus, inactivation of the granular uptake process by systemic administration of reserpine results in a decreased output of DA. This effect is consistent with the importance of the granular uptake mechanism for a normal dopaminergic transmission (Carlsson et al., 1957; Euler and Lishajko, 1963; Kopin, 1964; Dahlstrom et al., 1965). Consistent with an intraneuronal release and metabolism of stored DA consequent to inactivation of the granular uptake process (Weil-Malherbe and Bone, 1959; Andén et al., 1964; Laverty and Sharman, 1965; Sharman, 1966; Besson et al., 1971; Guldberg and Broch, 1971; Roffler-Tarlov et al., 1971) is the early shortlasting increase of DOPAC and HVA observed after reserpine. The mechanism of the later long-lasting reduction of acid metabolites, particularly DOPAC, is more difficult to explain at the moment. We suggest that inactivation of the granular uptake mechanism raises the intraneuronal concentration of DA and increases the extent of product inhibition of tyrosine hydroxylase. If this intcrpretation is correct, the granular uptake mechanism is important in order that newly synthesized DA, 

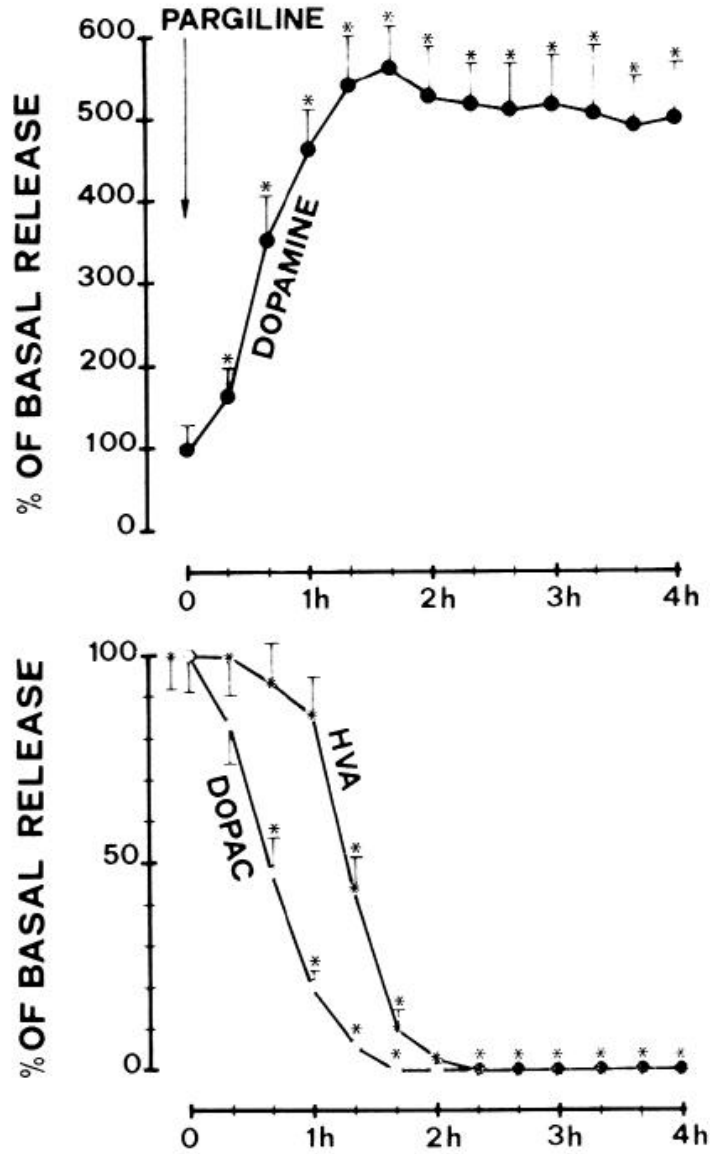

TIME AFTER PARGILINE

( $75 \mathrm{mg} / \mathrm{kg}$ i.p.)

Figure 11. Effect of pargyline $(75 \mathrm{mg} / \mathrm{kg}$, i.p.) on DA, DOPAC, and HVA outputs. Results are means \pm SEM of four experiments. Basal outputs were as follows: DA, $0.24 \pm 0.018$; DOPAC, $68 \pm 3.6$; HVA, $20 \pm 1.2 \mathrm{pmol} / 20 \mathrm{~min}($ mean $\pm \mathrm{SEM})$. $*, p<0.05$ with respect to basal values.

by accumulating in the cytoplasm, would not limit its own synthesis.

The output of DA and of its metabolites is markedly affected by inactivation of MAO by pargyline (Kopin, 1964). In agreement with an intraneuronal location of $\mathrm{MAO}$ and with the consequent increase of the intraneuronal concentrations of DA, pargyline increases DA release. As expected, DOPAC and HVA outputs fall to zero after pargyline. The decrease of the two metabolites is parallel but the fall of HVA takes place with a delay of about 20 min from that of DOPAC. This delay is consistent with the origin of most HVA as a product of DOPAC through COMT. The half-time of the decrease of DOPAC and HVA is about $20 \mathrm{~min}$, which compares favorably with that deduced from postmortem measurements of DOPAC and HVA after MAO inhibition (Wilk et al., 1975) and from in vivo voltammetry with electrodes which detect mostly DOPAC (Gonon et al., 1981).

Administration of reserpine to pargyline-treated rats results in a sharp peak of output of DA which then stabilizes to a level about twice that under pargyline alone. Thus, MAO inhibition not only prevents the fall of DA release produced by reserpine but actually increases it. This observation is consistent with the classic concept that reserpine depletes DA stores by making DA available to MAO action and that blockade of MAO activity prevents reserpine-induced depletion of DA stores (Spector et al., 1960; Kopin, 1964). The presence of large amounts of unmetabolized DA within the terminals as a result of the intraneuronal release of DA by reserpine is likely to be the cause of the release of DA obtained after the administration of reserpine to a pargyline-treated animal. In agreement with our data, reserpine produces behavioral excitation instead of sedation in pargyline-pretreated animals (Spector et al., 1960).

The effect of $\gamma$-BL on DA release and metabolism deserves comment. As noted above, the inhibition of DA release by $\gamma$-BL observed by us is consistent with the ability of this drug to block neuronal firing (Walters and Roth, 1972, 1974; Walters et al., 1973) and provides the first evidence that this drug indeed reduces or blocks DA release. Our present observations are in contrast with those of Cheramy et al. (1977), who reported that peripheral administration to cats of $\gamma$-hydroxybutyrate, the product of $\gamma$-BL metabolism, increased the release of labeled DA endogenously synthesized from labeled tyrosine. Indeed, the results of Cheramy et al. (1977) were difficult to reconcile with the large body of biochemical and electrophysiological evidence indicating that $\gamma$-hydroxybutyrate or its lactone $(\gamma-\mathrm{BL})$ blocks rather than stimulates DA transmission (Gessa et al., 1966, 1968; Bustos et al., 1972; Spano et al., 1972). The reason for the discrepancy between our results and those of Cheramy et al. (1977) is not readily apparent. One possibility is that the changes observed by Cheramy et al. reflect the stimulatory effect of $\gamma$-BL on the synthesis rather than its inhibitory action on the release of DA. The reason for this might be that Cheramy et al. do not estimate the release of endogenous unlabeled DA but rather the release of labeled DA endogenously synthesized from labeled tyrosine. However, since the results of Cheramy et al. were obtained in the cat and ours are obtained in the rat, the existence of a species difference cannot be excluded.

The changes produced by $\gamma$-BL in the output of DOPAC and HVA are biphasic, being characterized by a marked reduction which parallels the drop of DA release and a short-lasting increase which takes place as soon as the release of DA recovers toward basal values. We interpret the first phase as due to the reduced disposition of DA secondary to the reduction of release and the second phase as due to an intraneuronal disposition of previously accumulated DA coincident with the recovery of DA firing. The reason why, with recovery of DA firing, the release of DA takes place intraneuronally rather than extraneuronally is difficult to explain unless one postulates that $\gamma$-BL impairs exocytotic release and that this action is still present when that which results in blockade of firing is fading away.

Finally, amphetamine, a drug classically viewed as an indirectly acting sympathomimetic amine (Carlsson et al., 1966; Besson et al., 1969a, 1971; Chiueh and Moore, 1973, 1974, 1975; Von Voigtlander and Moore, 1973; Arnold et al., 1977), produces a sharp and dramatic release of DA at a dose $(1.0 \mathrm{mg} / \mathrm{kg}$ of the sulfate $)$ which 


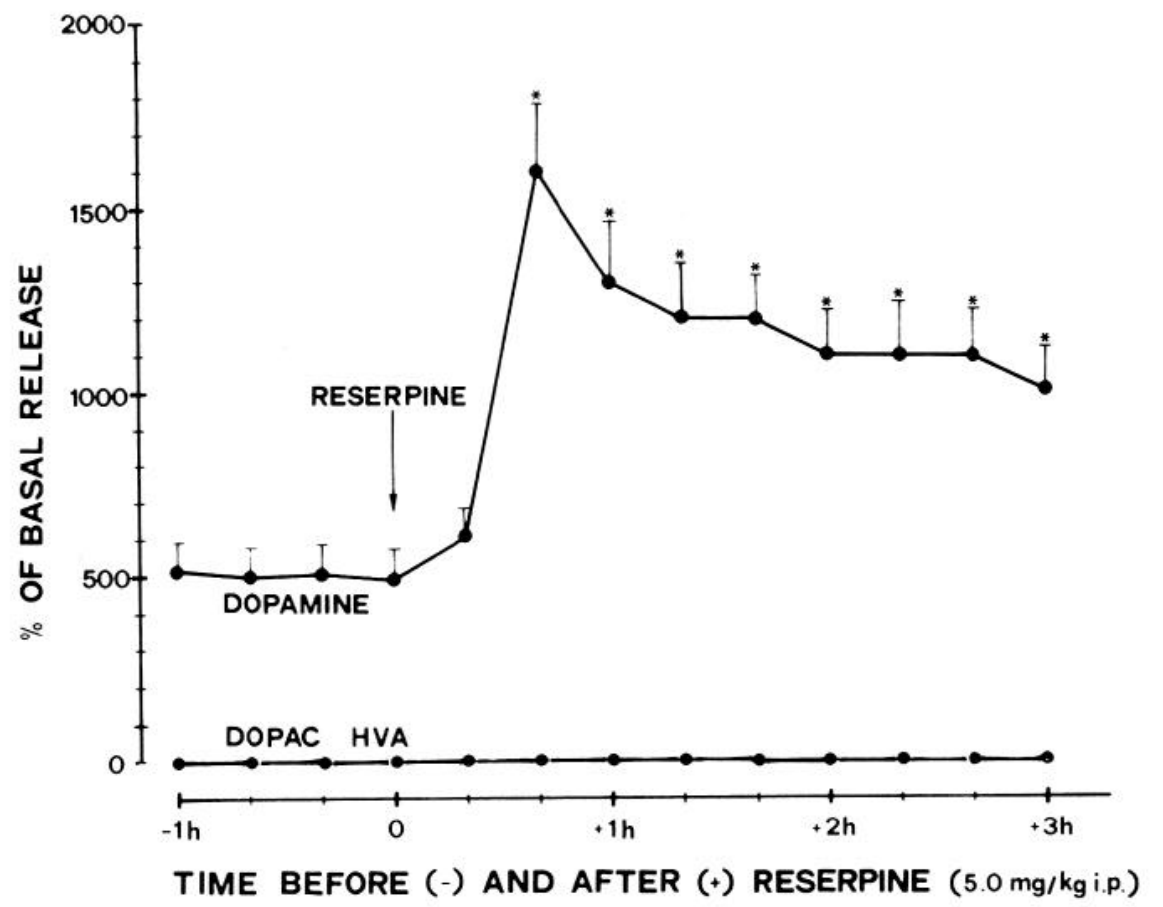

Figure 12. Effect of reserpine (5 mg/kg, i.p.) on DA, DOPAC, and HVA outputs in rats pretreated with pargyline $(75 \mathrm{mg} / \mathrm{kg}$, i.p.) $4 \mathrm{hr}$ in advance. Results are means \pm SEM of four experiments. The basal values to which the values are referred are those of the experiment reported in Figure $11 .{ }^{*}, p<0.05$ with respect to basal values.

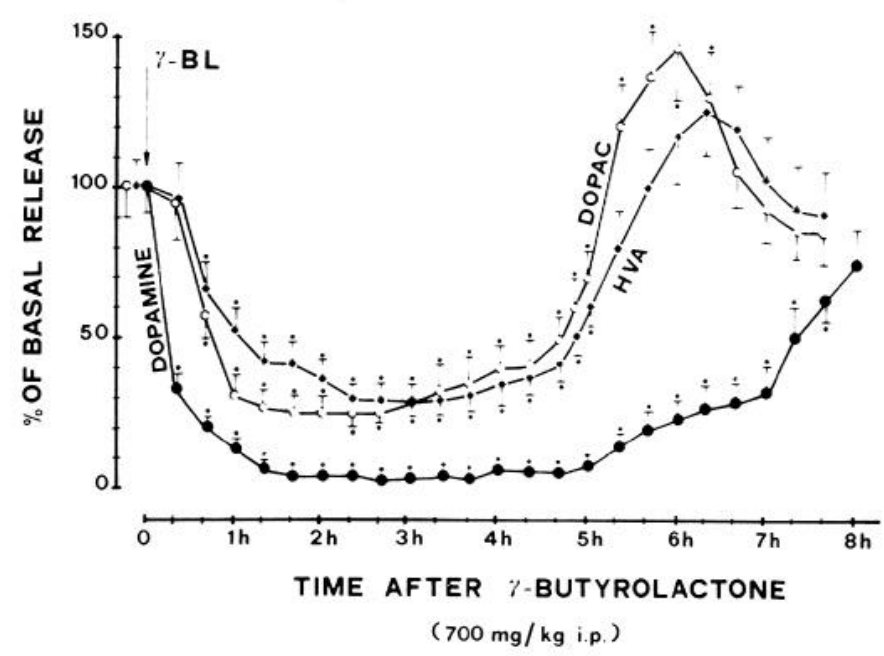

Figure 13. Effect of $\gamma$-butyrolactone $(\gamma-B L)(700 \mathrm{mg} / \mathrm{kg}$, i.p. $)$ on DA, DOPAC, and HVA outputs. Results are means \pm SEM of four experiments. Basal values were as follows: DA, $0.33 \pm$ 0.017 ; DOPAC, $72 \pm 3.8$; HVA, $31 \pm 1.7 \mathrm{pmol} / 20 \mathrm{~min}$ (mean \pm SEM). $*, p<0.05$ with respect to basal values.

is considered to produce low intensity behavioral stimulation. In agreement with the ability of amphetamine to shift DA from the intraneuronal to the extraneuronal compartment, DOPAC, the intraneuronal metabolite of DA, is drastically reduced (Sharman, 1966; Roffler-Tarlov et al., 1971; Wilk et al., 1975; Westerink and Korf, 1976b). HVA is also reduced, although with delay, indicating that its major origin is recaptured DA via DOPAC rather than released DA via 3-methoxytyramine (Wilk et al., 1975; Westerman and Korf, 1976a, b; Di Giulio et al., 1978; Westerink, 1979).
In conclusion the method described here has many characteristics which make it very appealing for the estimation of DA release in vivo. These features are the following. (1) Estimation not only of DA release but also of DA metabolism. This characteristic is very important, particularly when studying the effect of drugs which change the compartmentation or the metabolism of DA. Indeed we expect that studies with this method might help to clarify the mechanism of action of drugs acting on DA transmission. (2) Applicability to the most common laboratory animal, the rat, in which most of the studies on the anatomy, pharmacology, and electrophysiology of the DA system have been performed. (3) Estimation of the endogenous, unlabeled DA. This characteristic is of fundamental importance since it provides the most direct information on DA release and avoids the possible problems connected with the estimation of labeled DA formed from exogenously administered precursors. A further development of this technique might be the administration of labeled tyrosine to estimate, from the time course of the specific activity of DA, DOPAC, and HVA, the rate of synthesis and metabolism of DA.

The system in its present form is applied to halothaneanesthetized rats. However, it can be easily modified by fixing the dialysis tube with dental cement to the animal's head and connecting it to the pump through a liquid swivel in order to estimate DA release and metabolism in freely moving rats. This enables the correlation of changes in behavioral activity with changes in DA release and metabolism (A. Imperato and G. Di Chiara, manuscript in preparation). Moreover, it should be possible to apply the present technique to the estimation of the in vivo release in the striatum of other transmitters. 
Preliminary observations indicate that this is so for acetylcholine, serotonin, and enkephalins (A. Imperato and G. Di Chiara, manuscript in preparation).

\section{References}

Andén, N. E., B. E. Roos, and B. Werdinius (1964) Effects of chlorpromazine, haloperidol and reserpine on the levels of phenolic acids in rabbit corpus striatum. Life Sci. 3: 149.

Andén, N. E., K. Fuxe, B. Hamberger, and T. Hokfelt (1966) A quantitative study on the nigro-neostriatal dopamine neuron system in the rat. Acta Physiol. Scand. 67: 306-312.

Arnold, E. B., P. B. Molinolf, and C. O. Rutledge (1977) The release of endogenous norepinephrine and dopamine from cerebral cortex by amphetamine. J. Pharmacol. Exp. Ther. 202: 544-557.

Besson, M. J., A. Cheramy, and J. Glowinski (1969a) Effects of amphetamine and desmethylimipramine on amine synthesis and release in central catecholamine-containing neurons. Eur. J. Pharmacol. 7: 111-114.

Besson, M. J., A. Cheramy, P. Feltz, and J. Glowinski (1969b) Release of newly synthesized dopamine from dopamine-containing terminals in the striatum of the rat. Proc. Natl. Acad. Sci. U. S. A. 62: 741-748.

Besson, M. J., A. Cheramy, P. Feltz, and J. Glowinski (1971) Dopamine. Spontaneous and drug induced release from the caudate nucleus in the cat. Brain Res. 32: 407-424.

Besson, M. J., A. Cheramy, C. Gauchy, and J. Glowinski (1973) In vivo continuous estimation of ${ }^{3} \mathrm{H}$-dopamine synthesis and release in the cat caudate nucleus: Effects of $\alpha$-methylparatyrosine and of transection of the nigro-neostriatal pathway. Naunyn Schmiedeberg's Arch. Pharmacol. 278: 101105.

Bustos, G., M. J. Kuhar, and R. H. Roth (1972) Effect of gamma-hydroxybutyrate and gamma-butyrolactone on dopamine synthesis and uptake by rat striatum. Biochem. Pharmacol. 21: 2649-2652.

Carlsson, A., E. Rosengren, A. Bertler, and J. Nilsson (1957) Effect of reserpine on the metabolism of catecholamines. In Psychotropic Drugs, S. Garattini and V. Ghetti, eds., pp. 363372, Elsevier-North Holland Publishing Co., Amsterdam.

Carlsson, A., K. Fuxe, B. Hamberger, and M. Lindqvist (1966) Biochemical and histochemical studies on the effects of imipramine-like drugs and $(+)$-amphetamine on central and peripheral catecholamine neurons. Acta Physiol. Scand. 67: 481.

Chase, T. N., and I. J. Kopin (1968) Stimulus-induced release of substances from olfactory bulb using the push-pull cannula. Nature 217: 466-467.

Cheng, H. Y., J. Schenk, R. Huff, and R. N. Adams (1979) In vivo electrochemistry: Behaviour of microelectrodes in brain tissue. J. Electroanal. Chem. 100: 23-31.

Cheramy, A., A. Nieoullon, and J. Glowinski (1977) Stimulating effects of $\gamma$-hydroxybutyrate on dopamine release from the caudate nucleus and the substantia nigra of the cat. J. Pharmacol. Exp. Ther. 203: 283-293.

Chiueh, C. C., and K. E. Moore (1973) Release of endogenously synthesized catechols from the caudate nucleus by stimulation of the nigrostriatal pathway and by the administration of $d$-amphetamine. Brain Res. 50: 221-225.

Chiueh, C. C., and K. E. Moore (1974) In vivo rcleasc of endogenously synthesized catecholamines from the cat brain evoked by electrical stimulation and by $d$-amphetamine. $J$. Neurochem. 23: 159-168.

Chiueh, C. C., and K. E. Moore (1975) d-Amphetamine-induced relcase of "newly synthesized" and "stored" dopamine from the caudate nucleus in vivo. J. Pharmacol. Exp. Ther. 192: $642-653$.

Conti, J. C., E. Strope, R. N. Adams, and C. A. Marsden (1978) Voltammetry in brain tissue: Chronic recording of stimulated dopamine and 5-hydroxytryptamine. Life Sci. 23: 2705-2716.

Dahlstrom, A., K. Fuxe, and N. A. Hillarp (1965) Site of action of reserpine. Acta Pharmacol. Toxicol. (Copenh.) 22: 277 292.

Di Giulio, A. M., A. Groppetti, F. Cattabeni, C. L. Galli, A. Maggi, S. Algeri, and F. Ponzio (1978) Significance of dopamine metabolites in the evaluation of drugs acting on dopaminergic neurons. Eur. J. Pharmacol. 52: 201-207.

Elghozi, J. L., K. H. LeQuain-Bui, J. T. Earnhardt, P. Meyer, and M. A. Devynck (1981) In vivo dopamine release from the anterior hypothalamus of the rat. Eur. J. Pharmacol. 73: 199208.

Euler, U. S., and F. Lishajko (1963) Effect of reserpine on the uptake of catecholamines in isolated nerve storage granules. Int. J. Neuropharmacol. 2: 127-134.

Ewing, A. G., R. M. Wightman, and M. A. Dayton (1982) In vivo voltammetry with electrodes that discriminate between dopamine and ascorbate. Brain Res. 249: 361-370.

Felice, L. J., J. D. Felice, and P. T. Kissinger (1978) Determination of catecholamines in rat brain parts by reverse-phase ion-pair liquid chromatography. J. Neurochem. 31: 14611165.

Gaddum, J. H. (1961) Push-pull cannulas. J. Physiol. (Lond.) 155: $1 \mathrm{P}$.

Gauchy, C., B. Bioulac, A. Cheramy, M. J. Besson, J. Glowinski, and J. D. Vincent (1974) Estimation of chronic dopamine release from the caudate nucleus of the Macaca mulatta. Brain Res. 77: 257-268.

Gessa, G. L., L. Vargiu, F. Crabai, G. C. Boero, F. Caboni, and $R$. Camba (1966) Selective increase of brain dopamine induced by gamma-hydroxybutyrate. Life Sci. 5: 1921-1930.

Gessa, G. L., F. Crabai, L. Vargiu, and P. F. Spano (1968) Selective increase of brain dopamine induced by $\gamma$-hydroxybutyrate: Study of the mechanism of action. J. Neurochem. 15: $377-381$.

Glowinski, J., J. Axelrod, and L. I. Iversen (1966) Regional studies of catecholamines in the rat brain. IV. Effects of drugs on the disposition of ${ }^{3} \mathrm{H}$-norepinephrine and ${ }^{3} \mathrm{H}$-dopamine. J. Pharmacol. Exp. Ther. 153: 30.

Gonon, F., M. Buda, R. Cespuglio, M. Jouvet, and J.-F. Pujol (1980) In vivo electrochemical detection of catechols in the neostriatum of anaesthetized rats: Dopamine or DOPAC? Nature (Lond.) 268: 902-904.

Gonon, F. G., M. J. Buda, M. Jouvet, and J.-F. Pujol (1981) Voltammetry in the striatum of chronic freely moving rats: Detection of catechols and ascorbic acid. Brain Res., 223: 6980.

Guldberg, H. C., and O. J. Broch (1971) On the mode of action of reserpine on dopamine metabolism in the rat striatum. Eur. J. Pharmacol. 13: 155.

Hernandez, L., X. Paez, and C. Hamlin (1983) Neurotransmitters extraction by local intracerebral dialysis in anesthetized rats. Pharmacol. Biochem. Behav. 18: 159-162.

Johnson, R. D., and J. B. Justice (1983) Model studies for brain dialysis. Brain Res. Bull. 10: 567-571.

Konig, J. F. R., and R. A. Klippel (1963) The Rat Brain. A Stereotaxic Atlas of the Forebrain and Lower Parts of the Brain Stem, p. 162, Williams \& Wilkins, Baltimore.

Kopin, I. J. (1964) Storage and metabolism of catecholamines: The role of monoamine oxidase. Pharmacol. Rev. 16: 179191.

Laverty, R., and D. F. Sharman (1965) Modification by drugs of the metabolism of 3,4-dihydroxyphenylamine, noradrenaline and 5-hydroxytryptamine in the brain. Br. J. Pharmacol. Chemother. 24: 369-385.

Lloyd, K. G., and G. Bartholini (1975) The effect of drugs on the release of endogenous catecholamines into the perfusate of discrete brain areas of the cat in vivo. Experientia 31: 560561. 
McKenzie, G. M., and J. C. Szerb (1968) The effect of dihydroxyphenylalanine, pheniprazine and dextroamphetamine on the in vivo release of dopamine from the caudate nucleus. J. Pharmacol. Exp. Ther. 162: 302-308.

McLennan, H. (1964) The release of acetylcholine and 3hydroxytyramine from the caudate nucleus. J. Physiol. (Lond.) 174: 152-161.

Mefford, I. N. (1981) Application of high performance liquid chromatography with electrochemical detection to neurochemical analysis: Measurement of catecholamines. Serotonin and metabolites in rat brain. J. Neurosci. Methods 3: 207-224.

Myers, R. D. (1970) An improved push-pull cannula system for perfusing an isolated region of the brain. Physiol. Behav. 5: 243-246.

Myers, R. D. (1972) Methods for perfusing different structures of the brain. In Methods in Psychobiology, R. D. Myers, ed., Vol. II, pp. 169-211, Academic Press, Inc., London.

Nagatsu, T., M. Levitt, and S. Udenfriend (1961) Tyrosine hydroxylase: The initial step in NE biosynthesis. J. Biol. Chem. 239: 2910-2917.

Nieoullon, A., A. Cheramy, and J. Glowinski (1977) An adaption of the push-pull cannula method to study the in vivo release of ${ }^{3} \mathrm{H}$-dopamine synthesized from ${ }^{3} \mathrm{H}$-tyrosine in the cat caudate nucleus: Effect of various physical and pharmacological treatments. J. Neurochem. 28: 819-828.

Philippu, A., H. Dietl, and J. N. Sinha (1980) Rise in blood pressure increases the release of endogenous catecholamines in the anterior hypothalamus of the cat. Naunyn Schmiedeberg's Arch. Pharmacol. 310: 237.

Portig, P. J., and M. Vogt (1966) Search for substances released on stimulation of the caudate nucleus in the cat. J. Physiol. (Lond.) 186: 131-132.

Rech, R. H., H. K. Borys, and K. E. Moore (1966) Alterations in behaviour and brain catecholamine levels in rats treated with $\alpha$-methyltyrosine. J. Pharmacol. Exp. Ther. 153: 412419.

Refshauge, C., P. T. Kissinger, R. Dreiling, L. Blank, R. Freeman, and R. N. Adams (1974) New high performance liquid chromatographic analysis of catecholamines. Life Sci. 14: 311-322.

Riddell, D., and J. C. Szerb (1971) The release in vivo of dopamine synthesized from labelled precursor in the caudate nucleus of the cat. J. Neurochem. 18: 989-1006.

Roffler-Tarlov, S., D. F. Sharman, and P. Tegerdine (1971) 3,4Dihydroxyphenylacetic acid and 4-hydroxy-3-methoxyphenylacetic acid in the mouse striatum: A reflection of intra- and extra-neuronal metabolism of dopamine? Br. J. Pharmacol. 42: 343 .

Roth, R. H., L. Allikmets, and J. M. R. Delgado (1969) Synthesis and release of noradrenaline and dopamine from discrete regions of monkey brain. Arch. Int. Pharmacodyn. Ther. 181: $273-282$.

Rubin, R. P. (1970) The role of calcium in the release of neurotransmitter substances and hormones. Pharmacol. Rev. 22: $389-428$.

Sharman, D. F. (1966) Changes in the metabolism of 3,4dihydroxyphenylethylamine (dopamine) in the striatum of the mouse induced by drugs. Br. J. Pharmacol. Chemother. 28: 153.

Spano, P. F., A. Tagliamonte, L. Vargiu, R. Camba, and G. L. Gessa (1972) Effect of $\gamma$-butyrolactone on dopamine metabolism in the basal ganglia of normal and reserpinized rats. Riv. Farmacol. Ter. 3: 1-5.

Spector, S., R. Kuntzman, P. A. Shore, and B. B. Brodie (1960) Evidence for release of brain amines by reserpine in presence of monoamine oxidase inhibitors. Implication of monoamine oxidase in norepinephrine metabolism in brain. J. Pharmacol. 130: 256-261.
Spector, S., A. Sjordsma, and S. Udenfriend (1965) Blockade of endogenous NE synthesis by $\alpha$-methyl-tyrosine, an inhibitor of tyrosine hydroxylase. J. Pharmacol. 147: 86-95.

Stadler, H., M. Gadea-Ciria, and G. Bartholini (1975) In vivo release of endogenous neurotransmitters in cat limbic regions: Effects of chlorpromazine and of electrical stimulation. Naunyn Schmiedeberg's Arch. Pharmacol. 288: 1-6.

Szerb, J. C. (1967) Model experiments with Gaddum's pushpull cannulas. Can. J. Physiol. Pharmacol. 45: 613-620.

Tilson, H. A., and S. B. Sparber (1972) Studies on the concurrent behavioral and neurochemical effects of psychoactive drugs using the push-pull cannula. J. Pharmacol. Exp. Ther. 181: $387-398$.

Ungerstedt, U., M. Herrera-Marschitz, U. Jungnelius, L. Stahle, U. Tossman, and T. Zetterstrom (1982) Dopamine synaptic mechanisms reflected in studies combining behavioural recordings and brain dialysis. In Dopamine, M. Kohsaka, J. N. Woodruff, T. Shohmuri, and Y. Tsukuda, Pergamon Press, New York.

Vogt, M. (1969) Release from brain tissue of compounds with possible transmitter function: Interaction of drugs with these substances. Br. J. Pharmacol. 37: 325-337.

Von Voigtlander, P. F., and K. E. Moore (1973) Involvement of nigro-striatal neurons in the in vivo release of dopamine by amphetamine, amantadine and tyramine. J. Pharmacol. Exp. Ther. 184: 242-252.

Walters, J. R., and R. H. Roth (1972) Effect of gamma-hydroxybutyrate on dopamine and dopamine metabolites in the rat striatum. Biochem. Pharmacol. 21: 2111-2121.

Walters, J. R., and R. H. Roth (1974) Dopaminergic neurons: Drug-induced antagonism of the increase in tyrosine hydroxylase activity produced by cessation of impulse flow. J. Pharmacol. Exp. Ther. 191: 82-91.

Walters, J. R., R. H. Roth, and G. K. Aghajanian (1973) Dopaminergic neurons: Similar biochemical and histochemical effects of $\gamma$-hydroxybutyrate and acute lesions of the nigro-neostriatal pathway. J. Pharmacol. Exp. Ther. 186: 630-639.

Weil-Malherbe, H., and A. D. Bone (1959) The effect of reserpine on the intracellular distribution of catecholamines in the brain stem of the rabbit. J. Neurochem. 4: 251-263.

Weissman, A., and B. K. Koe (1965) Behavioural effects of $\gamma$ $\chi$-methyltyrosine, an inhibitor of tyrosine hydroxylase. Life Sci. 4: 1037-1048.

Westerink, B. H. C. (1979) Further studies on the sequence of dopamine metabolism in the rat brain. Eur. J. Pharmacol. 56: 313

Westerink, B. H. C., and J. Korf (1976a) Turnover of acid dopamine metabolites in striatal and mesolimbic tissue of the rat brain. Eur. J. Pharmacol. 37: 249.

Westerink, B. H. C., and J. Korf (1976b) Comparison of effects of drugs on dopamine metabolism in the substantia nigra and the corpus striatum of rat brain. Eur. J. Pharmacol. 40: 131.

Wightman, R. M., E. R. Strope, P. Plotsky, and R. N. Adams (1976) Monitoring of transmitter metabolites by voltammetry in cerebrospinal fluid following neural pathway stimulation. Nature (Lond.) 262: 145-146.

Wightman, R. M., E. Strope, P. Plotsky, and R. N. Adams (1978) In vivo voltammetry: Monitoring of dopamine metabolites in CSF following release by electrical stimulation. Brain Res. 159: 55-68.

Wilk, S., E. Watson, and B. Travis (1975) Evaluation of dopamine metabolism in rat striatum by a gas chromatographic technique. Eur. J. Pharmacol. 30: 238.

Yaksh, T. L., and H. I. Yamamura (1974) Factors affecting performance of the push-pull cannula in brain. J. Appl. Physiol. 37: 428-434. 